\title{
A new therapeutic option for postoperative pain management with oxycodone HCI injection
}

\author{
Byung Moon Choi \\ Department of Anesthesiology and Pain Medicine, Asan Medical Center, University of Ulsan College of Medicine, \\ Seoul, Korea
}

Fentanyl is the most commonly used opioid analgesic in intravenous patient-controlled analgesia (IV PCA) in Korea. IV oxycodone was approved for postoperative IV PCA by the Ministry of Food and Drug Safety of Korea in 2013. The approved dosage regimen for postoperative pain relief with IV oxycodone is IV bolus loading of $2 \mathrm{mg}$ followed by PCA composed of demand boluses of $1 \mathrm{mg}$ and no background infusion with an oxycodone concentration of $1 \mathrm{mg} / \mathrm{ml}$. However, a simulation study indicated that the minimum effective analgesic concentration (MEAC, as indicated by relief of pain by administering rescue analgesics) of oxycodone was reached most quickly with a higher loading dose of $0.1 \mathrm{mg} /$ $\mathrm{kg}$ and IV PCA with background infusion. Oxycodone is a therapeutic option as an analgesic for postoperative pain management. It is necessary to reduce the analgesic dose of oxycodone in elderly patients because metabolic clearance decreases with age.

Key Words: Patient-controlled analgesia, Postoperative pain.

\section{Introduction}

Oxycodone is a $\mu$-opioid receptor agonist and is generally indicated for the relief of moderate to severe pain $[1,2]$. In recent years, the use of intravenous (IV) oxycodone has increased markedly [2]. As a result, it has replaced morphine as the first choice opioid in several countries [2]. In Korea, IV oxycodone was approved for postoperative IV patient-controlled analgesia (IV PCA) by the Ministry of Food and Drug Safety (MFDS)

\footnotetext{
Corresponding author: Byung Moon Choi, M.D., Ph.D.

Department of Anesthesiology and Pain Medicine, Asan Medical Center, University of Ulsan College of Medicine, 88, Olympic-ro 43-gil, Songpa-gu, Seoul 05505, Korea

Tel: 82-2-3010-1704, Fax: 82-2-3010-6790

E-mail: byungmoonchoi7@gmail.com

ORCID: http://orcid.org/0000-0002-6561-8851
}

Received: January 5, 2016.

Accepted: February 2, 2016.

Korean J Anesthesiol 2016 June 69(3): 211-218

http://dx.doi.org/10.4097/kjae.2016.69.3.211 in 2013. The approved dosage regimen for postoperative pain relief with IV oxycodone is IV bolus loading of $2 \mathrm{mg}$ followed by PCA composed of demand boluses of $1 \mathrm{mg}$ and no background infusion with an oxycodone concentration of $1 \mathrm{mg} / \mathrm{ml}$. In Korea, the most common opioid analgesic used in IV PCA is fentanyl, and clinical experience of IV PCA with oxycodone is extremely limited. Although developed in an attempt to improve on the existing opioids, oxycodone has similar adverse effects to those typically found with opioids. An earlier study showed that intermittent administration of IV oxycodone up to $15 \mathrm{mg}$ provided better analgesia than fentanyl at a dose of $200 \mu \mathrm{g}$, but caused more side effects [3]. Moreover, previous studies of postoperative pain management with IV oxycodone were limited in sample size, mostly to less than 100 patients, which may not be large enough to assess the safety of IV oxycodone $[3,4]$. This review discusses the pharmacokinetic characteristics of oxycodone and appropriate regimens of patient-controlled oxycodone. In addition, the analgesic effects of patient-controlled oxycodone for postoperative pain management are compared with those of patient-controlled fentanyl.

(c) This is an open-access article distributed under the terms of the Creative Commons Attribution Non-Commercial License (http://creativecommons.org/ licenses/by-nc/4.0/), which permits unrestricted non-commercial use, distribution, and reproduction in any medium, provided the original work is properly cited. 


\section{Clinical Pharmacology of Oxycodone}

Oxycodone is a semisynthetic opioid synthesized from poppyderived thebaine [1]. This agent was developed in 1916 in Germany as one of several new semisynthetic opioids in an attempt to improve on the existing opioids [1]. It is a narcotic analgesic generally indicated for relief of moderate to severe pain.

\section{Mechanism of Action}

Oxycodone is a semisynthetic, $\mu$-opioid receptor agonist with analgesic effects in several pain conditions [1]. Ross and Smith [5] proposed that oxycodone acts on $\kappa$-opioid receptors. They also suggested that oxycodone may be a $\kappa 2 b$-opioid agonist [6]. Nozaki et al. [7] suggested that the effect of oxycodone is mediated by different receptors in different situations. Specifically, in diabetic mice, the $\kappa$-opioid receptor appears to be involved in the antinociceptive effects of oxycodone, while in nondiabetic mice, the $\mu 1$-opioid receptor seems to be primarily responsible for its effects [8].

\section{Potency}

Oxycodone and morphine are presumed to have a 1:1 ratio of analgesic potency in postoperative pain after surgery, with mixed somatic and visceral pain components $[9,10]$. In Korea, fentanyl is the most commonly used opioid for PCA-based postoperative pain management. However, no safe recommendations concerning the direct conversion factor of IV oxycodone and fentanyl dosage have yet been reported. In a previous study, the median consumption levels of oxycodone and fentanyl were $15 \mathrm{mg}$ and $200 \mu \mathrm{g}$, respectively, and the intensity of abdominal pain was significantly lower in the oxycodone group, indicating that the potency ratio of oxycodone to fentanyl was less than $75: 1[2,3]$. In a recent pilot study, the potency ratio was $60: 1$ in patients undergoing laparoscopic gynecological surgery [11].

\section{Minimum Effective Concentration (MEC) and Minimum Effective Analgesic Concentration (MEAC)}

The analgesic effects of opioids are related to their plasma concentration. Either mean effective concentration (MEC) or minimum effective analgesic concentration (MEAC) is used to assess concentration-effect relationships. MEC is the concentration at the time re-medication is required. MEAC can be determined by constant-rate infusions of the opioid until steady-state concentrations are reached, at which time the drug concentration will have equilibrated between plasma and effect-site com-

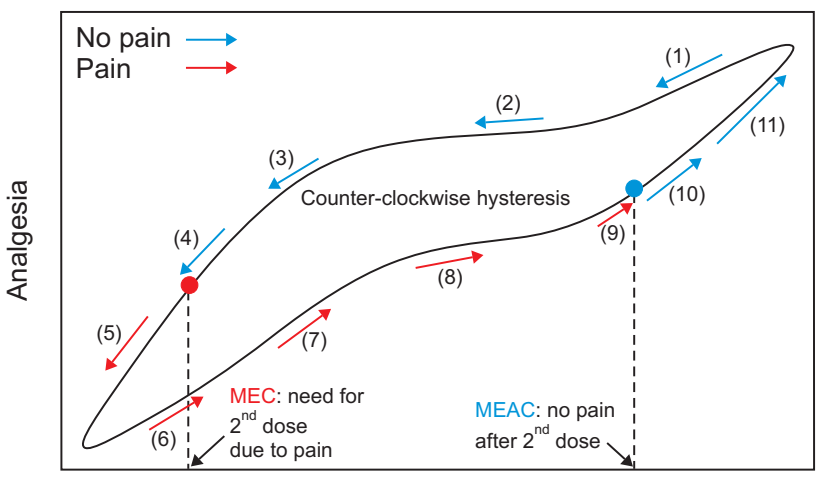

Cp of oxycodone

Fig. 1. Minimum effective concentration (MEC) and minimum effective analgesic concentration (MEAC) of intravenous (IV) oxycodone. Cp: plasma concentration.

partments containing its receptors, and the drug concentration eliciting analgesia can be determined (Fig. 1). The MEC and MEAC of IV oxycodone were reported as $20-35 \mathrm{ng} / \mathrm{ml}$ and $45-50 \mathrm{ng} / \mathrm{ml}$ in patients with laparoscopic cholecystectomy, respectively [12]. In cardiac surgical patients, MEC and MEAC of oxycodone are $6-12 \mathrm{ng} / \mathrm{ml}$ and $15-25 \mathrm{ng} / \mathrm{ml}$, respectively $[12,13]$. These observations suggest that the MEC and MEAC of oxycodone may differ between different types of surgery. Moreover, oxycodone has not been evaluated for MEC and MEAC in major intraabdominal surgery. The MEC and MEAC of fentanyl in such surgery are $0.63 \mathrm{ng} / \mathrm{ml}$ and $0.6-1.0 \mathrm{ng} / \mathrm{ml}$, respectively $[14,15]$.

\section{Metabolism by the Cytochrome P450 Enzyme System}

Oxycodone is metabolized by the cytochrome P450 enzyme system in the liver with the major metabolic pathway, CYP3A4, and the minor metabolic pathway, CYP2D6 [16,17]. Oxycodone metabolism through the CYP3A pathway should represent well over half of the metabolism of this drug in most patients. The importance of the CYP3A pathway for oxycodone metabolism was demonstrated by the estimated 2- to 14 -fold higher in vitro intrinsic clearance for $\mathrm{N}$-dealkylation as compared to Odemethylation through CYP2D6 [18]. Urinary metabolites derived from CYP3A-mediated N-demethylation of oxycodone (noroxycodone, noroxymorphone, and $\alpha$ - and $\alpha$-noroxycodol) accounted for $45 \% \pm 21 \%$ of the dose, whereas CYP2D6-mediated $\mathrm{O}$-demethylation (oxymorphone and $\alpha$ - and $\beta$-oxymorphol) and 6-keto-reduction ( $\alpha$ - and $\beta$-oxycodol) accounted for $11 \% \pm$ $6 \%$ and $8 \% \pm 6 \%$ of the dose, respectively. Noroxycodone and noroxymorphone were the major metabolites in the circulation with elimination half-lives longer than that of oxycodone, but their uptake into rat brain was significantly lower compared 
with the parent drug [19]. Oxymorphone is a more potent opioid agonist with stronger and higher binding affinity to $\mu$-opioid receptors than oxycodone [20]. However, the central opioid effects of oxycodone are governed by the parent drug, with a negligible contribution from its circulating oxidative and reductive metabolites [19]. CYP3A4-mediated N-demethylation makes oxycodone vulnerable to drug interaction, e.g., decreased or increased systemic exposure of oxycodone by rifampin, a CYP3A inducer, or itraconazole, a CYP3A4 inhibitor [21,22]. CYP2D6 has been reported to be unimportant for the clinical effect of oxycodone, despite great interindividual variation of the metabolism of CYP2D6 substrates due to differences in allele functionality $[18,23]$. Poor metabolizers (PM) have two nonfunctional alleles, while extensive metabolizers (EM) are homozygous with two functional alleles or heterozygous with one functional allele, and ultrarapid metabolizers (UM) have more than two functional alleles. There are pronounced interethnic differences in the allele distribution. Previous studies indicated that oxycodone concentrations are similar in CYP2D6 PM and reduced in CYP2D6 UM in comparison with CYP2D6 EM [18]. There are no clinically relevant drug interactions between IV oxycodone and inhibitors of CYP2D6, such as paroxetine [16]. However, Stamer et al. [24] demonstrated that the oxymorphone/oxycodone ratio was lowest, and oxycodone consumption up to the 12th hour was highest, in CYP2D6 PM in the setting of postoperative IV patient-controlled analgesia. The PM phenotype is attributed mainly to the CYP2D $6 * 3, * 4, * 5$, and *6 alleles, which predict $93 \%-98 \%$ of PMs in whites $[25,26]$. In contrast, certain nonfunctional allelic variants (CYP2D6*3, *4, and $* 6$ ) have not been observed in Asians, including Koreans [27-30]. The CYP2D6*10 allele, the most common allele in Asians, including Koreans, at frequencies of up to $60 \%$ (45.58\% in Koreans), is a reduced function allele and contributes to intermediate metabolism in a large number of Asian subjects $[29,31]$. Phenotypic studies have revealed that approximately $5 \%-10 \%$ of whites are PM [32-34], while the proportion is less than $1 \%$ in Asian populations [25,30,35]. Therefore, CYP2D6 genotyping to characterize the pharmacokinetics of oxycodone in Koreans is not likely to produce clinically significant results. If both oxidative metabolic pathways via CYP3A4 and 2D6 are inhibited, exposure to IV oxycodone increases substantially [16]. A similar effect is to be expected with use of a CYP3A inhibitor in CYP2D6 PM [18].

\section{Age and Clearance of Oxycodone}

Previous studies indicated the age dependency of oxycodone pharmacokinetics [36,37]. The pharmacokinetics of $5 \mathrm{mg}$ of IV oxycodone in four groups of 10-11 patients, aged 20-40, 60-70, and 70-90 years, were evaluated by non-compartmental analysis [36]. In the oldest group, the mean $\mathrm{AUC}_{\text {inf }}$ (area under the concentration-time curve from time zero to infinity) of oxycodone was $80 \%$ greater and the metabolic clearance was $34 \%$ lower than in the youngest group (both $\mathrm{P}<0.05$ ) [36]. In addition, age was a significant covariate on metabolic clearance of a pharmacokinetic model of oxycodone, and simulations of repetitive bolus administration showed a $20 \%$ increase in oxycodone concentration in the elderly [37]. Therefore, it is important to titrate the analgesic dose of oxycodone individually, particularly in the elderly.

\section{Adverse Drug Reactions}

Oxycodone shows the same adverse effects as those typically found for opioids, with constipation (25\%-30\%), nausea (25\%-30\%), and drowsiness (25\%) being the three most common symptoms [38]. Vomiting, pruritus, and dizziness occur in $5 \%-15 \%$ of patients taking oxycodone. Other effects, such as loss of appetite, nervousness, abdominal pain, diarrhea, urine retention, dyspnea, hiccups, headaches, dry mouth, hallucinations, and bronchospasm present in less than $5 \%$ of patients. ${ }^{1)}$ In high doses, overdoses, or in patients not tolerant to opiates, oxycodone can cause shallow breathing, bradycardia, cold clammy skin, apnea, hypotension, miosis, circulatory collapse, respiratory arrest, and death. ${ }^{1)}$

\section{Pharmacokinetic Simulation of Intravenous PCA Regimen with Oxycodone}

Saari et al. [37] characterized the population pharmacokinetics of oxycodone using pharmacokinetic data from patients and healthy volunteers (Table 1). The results showed that central volume and metabolic clearance of oxycodone are increased with increasing lean body mass. With increasing age, metabolic clearance is decreased, which is consistent with the noncompartmental pharmacokinetic analysis of Liukas et al. [36].

Table 1. Population Pharmacokinetic Parameters of Intravenous Oxycodone [37]

\begin{tabular}{cl}
\hline Parameters & \multicolumn{1}{c}{ Values } \\
\hline$V_{1}, \mathrm{~L}$ & $161+5.0 \times(\mathrm{LBM}-54.58)$ \\
$V_{2}, \mathrm{~L}$ & 124 \\
$\mathrm{Cl}, \mathrm{L} / \mathrm{h}$ & $48.1+0.547 \times(\mathrm{LBM}-54.58)-0.1777 \times($ age -44.81$)$ \\
$\mathrm{Q}, \mathrm{L} / \mathrm{h}$ & 982
\end{tabular}

LBM: lean body mass (calculated by the James formula).

${ }^{11}$ http://app.purduepharma.com/xmlpublishing/pi.aspx?id=o. Last access: 2013-06-07 
This simulation study was based on pharmacokinetic parameters and values of MEC, as indicated by the need to administer IV opioid due to pain, and MEAC, as indicated by relief of pain by administering opioid for oxycodone determined in previous studies $[12,37,39]$. Deterministic simulations that did not consider either interindividual or intraindividual random variability were performed using Asan Pump software (ver. 2.1.3; Bionet Co. Ltd., Seoul, Korea, http://www.fit4nm.org/download, last accessed: Aug 27, 2012).

\section{Bolus Loading}

When administered at the end of surgery, oxycodone at a dose of $2 \mathrm{mg}$ produced plasma concentrations over time less than the MEC (Fig. 2A). However, oxycodone at a dose of 0.1 $\mathrm{mg} / \mathrm{kg}$ (6 mg in a 60-kg subject) produced concentrations higher than MEC for 1 hour after the end of surgery (Fig. 2B). As lean body mass (LBM) was shown to be a significant covariate for central volume of oxycodone in the pharmacokinetic model of Saari et al. [37] (Table 1), plasma concentrations of oxycodone for approximately 1 hour after the end of surgery were higher in female patients with lower LBM, calculated by the James formula. Therefore, the loading dose of oxycodone administered at the end of surgery should be $0.1 \mathrm{mg} / \mathrm{kg}$, rather than $2 \mathrm{mg}$, to relieve immediate postoperative pain in the postanesthetic care unit.

\section{Background Infusion}

In another simulation, an IV oxycodone loading dose of 2 $\mathrm{mg}$ or $0.1 \mathrm{mg} / \mathrm{kg}$ was administered at the end of surgery and IV PCA with or without $1 \mathrm{mg} / \mathrm{h}$ background infusion was started 5 minutes later. Table 2 summarizes the time to reach MEAC, the time to reach $90 \%$ steady-state concentration, and the steady-state concentration of oxycodone. During the immediate postoperative period, MEAC was reached most quickly with a higher loading dose $(0.1 \mathrm{mg} / \mathrm{kg})$ and IV PCA with background infusion. Even with this regimen, rescue analgesic may be required to relieve pain for at least 2 hours after the end of surgery (Fig. 3). Time to $90 \%$ steady-state was shorter with a higher loading dose of oxycodone $(0.1 \mathrm{mg} / \mathrm{kg}, 6 \mathrm{mg})$ compared to load-
A

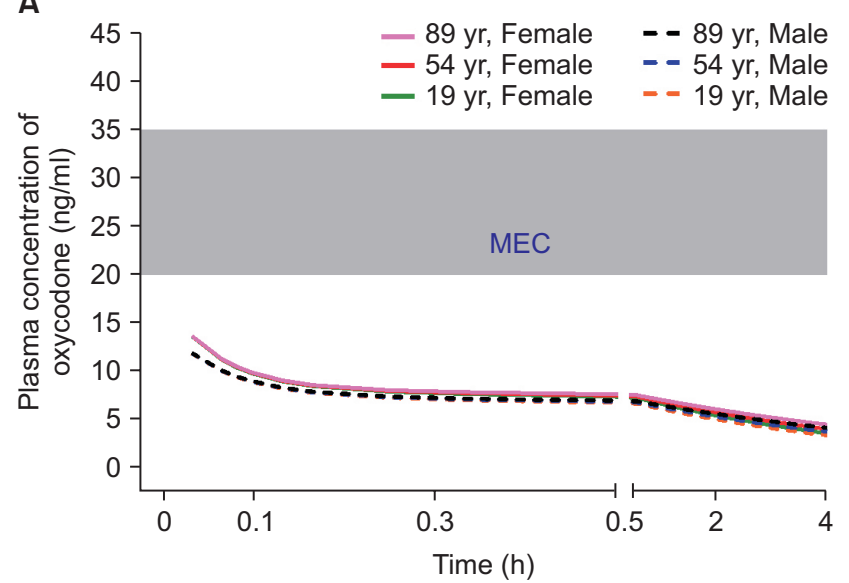

B

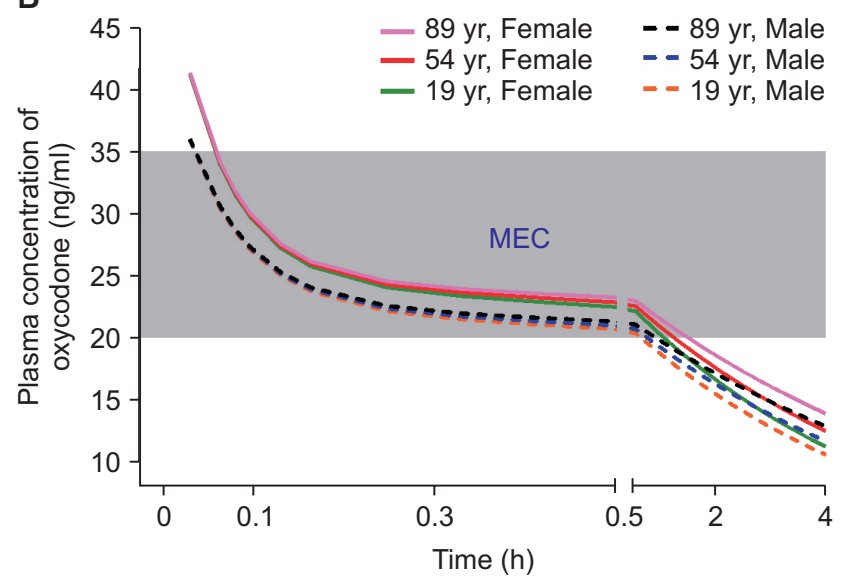

Fig. 2. Predicted concentration of oxycodone in the plasma over time after IV administration of a bolus of $2 \mathrm{mg}$ (A) or $0.1 \mathrm{mg} / \mathrm{kg}$ (B). The body weights and heights of all individuals were $60 \mathrm{~kg}$ and $165 \mathrm{~cm}$, respectively. MEC: minimum effective concentration.

Table 2. Time to Minimum Effective Analgesic Concentration and 90\% Steady-state, and Plasma Concentration at Steady-state in Intravenous (IV) Patient-controlled Analgesia with Oxycodone

\begin{tabular}{lcccc}
\hline \multicolumn{1}{c}{ Loading dose } & 2 mg & & $0.1 \mathrm{mg} / \mathrm{kg}$ \\
\hline Background infusion of $1 \mathrm{mg} / \mathrm{h}$ & - & + & - & + \\
Time to MEAC, $\mathrm{h}$ & 4 & 2.7 & 2.5 & 2 \\
Time to 90\% SS, h & $11-16$ & $11-16$ & $9-14$ & $9-14$ \\
Cp at SS, $\mathrm{ng} / \mathrm{ml}$ & $79-113$ & $99-142$ & $79-113$ & $99-142$ \\
\hline
\end{tabular}

The data show the predicted oxycodone concentration in the plasma over time in hypothetical male and female subjects aged 19, 54, and 89 years after receiving an IV bolus of $2 \mathrm{mg}$ or $0.1 \mathrm{mg} / \mathrm{kg}$ followed by demand boluses of $1 \mathrm{mg}$ every 15 minutes with or without background infusion at $1 \mathrm{mg} / \mathrm{h}$. The body weights and heights of all subjects were $60 \mathrm{~kg}$ and $165 \mathrm{~cm}$, respectively. MEAC: minimum effective analgesic concentration, SS: steady-state, $\mathrm{Cp}$ at SS: plasma concentration at steady-state. 
A

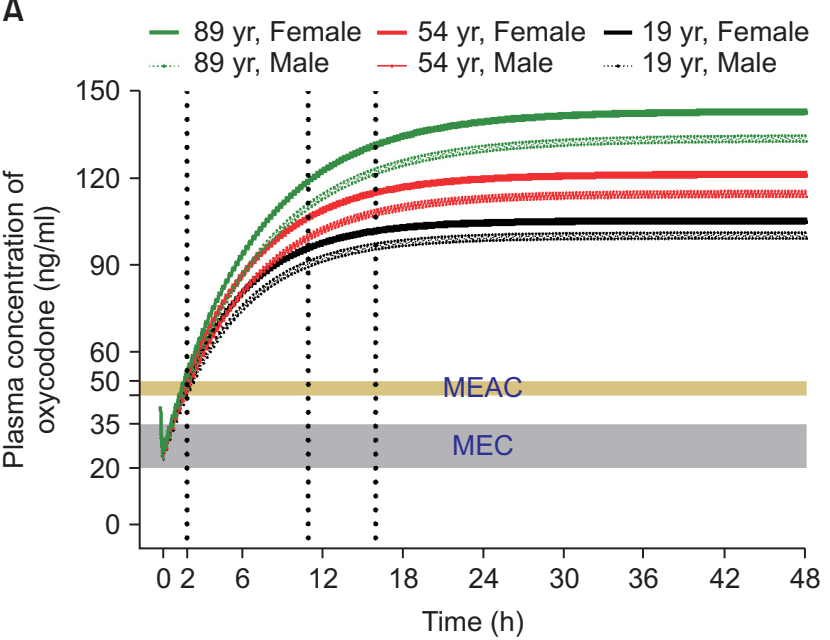

C

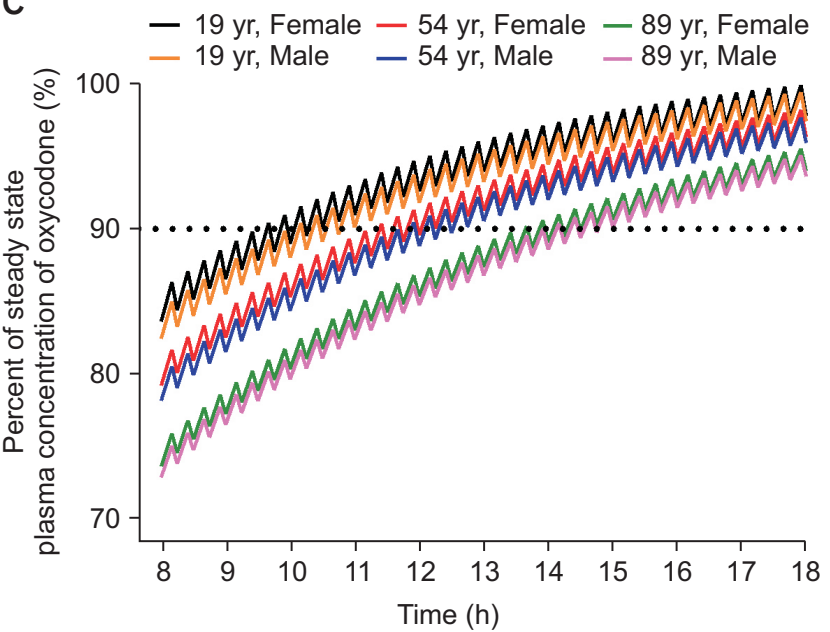

ing dose of $2 \mathrm{mg}$, while unaffected by background infusion of 1 $\mathrm{mg} / \mathrm{h}$. The steady-state concentration achieved was higher with the IV PCA regimen with background infusion, regardless of the loading dose. As LBM and age are significant covariates for metabolic clearance of oxycodone (Table 1), steady-state concentrations tended to be higher with increasing age and decreasing LBM. Steady-state concentrations for the dosage regimens in this simulation were approximately two to three times higher than the MEAC of oxycodone.

The dosage regimen for postoperative pain relief with IV oxycodone approved by MFDS is an IV bolus loading of $2 \mathrm{mg}$ followed by patient-controlled analgesia with demand bolus of 1 mg and no background infusion. Earlier studies on IV PCA with oxycodone did not include background infusion $[4,24,40]$. However, the pharmacokinetic simulation demonstrated that MEAC of oxycodone was reached most quickly with higher loading dose $(0.1 \mathrm{mg} / \mathrm{kg})$ and IV PCA with background infusion, which may reduce the necessity of rescue analgesic during the immediate postoperative period.

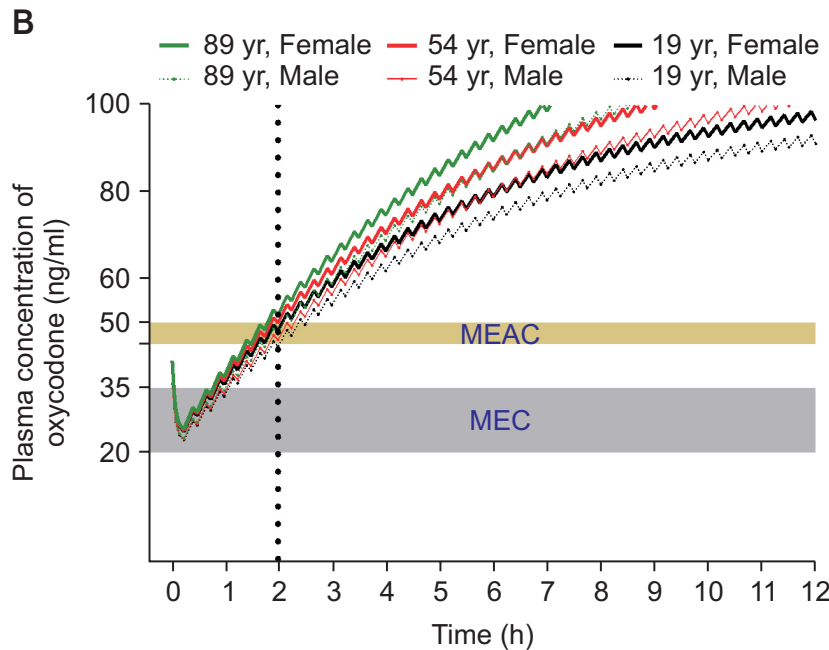

Fig. 3. Predicted concentration of oxycodone in the plasma over time after IV administration of a bolus of $0.1 \mathrm{mg} / \mathrm{kg}$ followed by demand boluses of $1 \mathrm{mg}$ every 15 minutes and background infusion of $1 \mathrm{mg} /$ h. (A) The entire time-concentration curve. (B) Time-concentration curve of time to reach MEAC. (C) Time-concentration curve of time to reach $90 \%$ steady-state concentration of oxycodone. Body weights and heights of all individuals were $60 \mathrm{~kg}$ and $165 \mathrm{~cm}$, respectively. MEAC: minimum effective analgesic concentration, MEC: minimum effective concentration. Demand bolus, background infusion rate, and lock-out time of postoperative IV patient-controlled analgesia (IV PCA) were set at $1 \mathrm{ml}, 1 \mathrm{ml} / \mathrm{h}$, and 15 minutes, respectively. The concentration of oxycodone in IV PCA was $1 \mathrm{mg} / \mathrm{ml}$. The pharmacokinetic model of Saari et al. was applied to this simulation [37]. Vertical dotted lines indicate time to reach MEAC ( 2 hours) and $90 \%$ steady-state concentration (9-14 hours). Time 0 indicates the end of surgery.

\section{Comparison of Analgesic Effects with Fentanyl}

When comparing the analgesic effects of two patientcontrolled opioids, it is important to determine the PCA dosage regimens of the two opioids because they affect the efficacy of analgesia. Previous studies have shown that the potency ratio of oxycodone to morphine is $1: 1$, whereas that of morphine to fentanyl is $100: 1[9,41]$. Two studies comparing patientcontrolled oxycodone and fentanyl in patients undergoing laparoscopic cholecystectomy and hysterectomy showed that the cumulative oxycodone dose was lower than that of fentanyl $[42,43]$. Moreover, a study comparing patient-controlled oxycodone and fentanyl in patients undergoing laparoscopic hysterectomy or myomectomy showed that, with a potency ratio of oxycodone to fentanyl of $60: 1$, the two opioids had similar analgesic effects [11]. Thus, Koch et al. showed that in patients undergoing laparoscopic cholecystectomy, intermittent administration of IV oxycodone up to $15 \mathrm{mg}$ yielded better analgesia than fentanyl at 
$200 \mu \mathrm{g}$, indicating that the potency ratio of oxycodone to fentanyl was less than $75: 1[2,3]$. Similarly, a pilot study by Park et al. [11] showed that oxycodone was more effective than fentanyl after laparoscopic gynecological surgery at a ratio of $100: 1$, and that the two analgesics were equipotent at $60: 1$. However, the sample sizes of these studies were relatively small, which may limit their reliability. Studies testing various potency ratios in a large cohort are needed to determine the appropriate potency ratio of oxycodone to fentanyl. Moreover, previous studies for

Table 3. Population Pharmacokinetic Parameters of Intravenous Fentanyl [44]

\begin{tabular}{ll}
\hline Parameters & Values \\
\hline$V_{1}, \mathrm{~L}$ & 13.0 \\
$k_{10},(/ \mathrm{min})$ & 0.0492 \\
$k_{12},(/ \mathrm{min})$ & 0.380 \\
$k_{13},(/ \mathrm{min})$ & 0.179 \\
$k_{21},(/ \mathrm{min})$ & 0.0960 \\
$\left.k_{31}, / \mathrm{min}\right)$ & 0.0077 \\
$k_{e 0},(/ \mathrm{min})$ & 0.147 \\
\hline
\end{tabular}

A

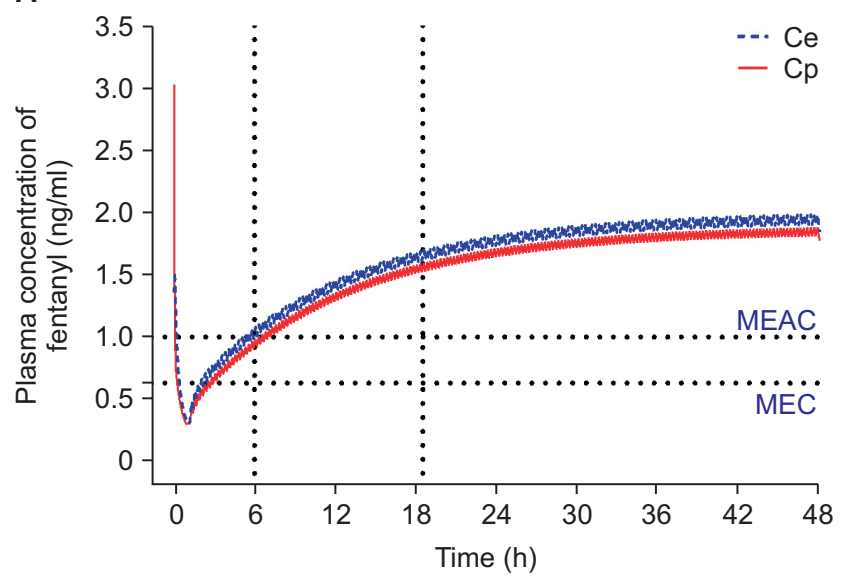

C

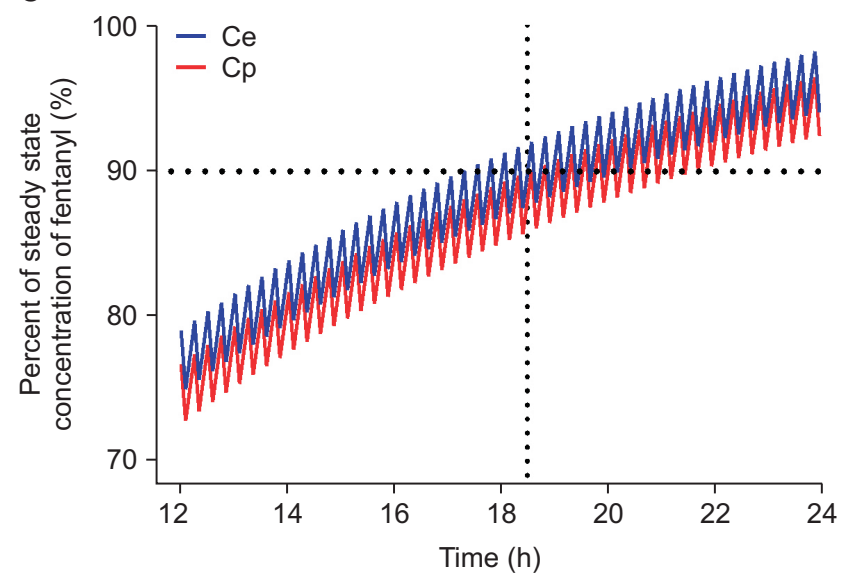

postoperative pain management with IV oxycodone were limited in sample size, mostly to less than 100 patients, which may not be large enough to assess the safety of IV oxycodone $[3,4]$. Therefore, the effectiveness and tolerability of IV PCA with oxycodone should be evaluated in large-scale clinical trials in Korean surgical populations. In addition, the population pharmacokinetics of oxycodone should also be characterized in Korean surgical patients to further adjust the optimal dosage regimen.

Based on population pharmacokinetic models of fentanyl reported by Scott et al. [44] (Table 3), plasma and effect-site concentrations of fentanyl were simulated using an Asan pump for comparison with oxycodone. The fentanyl PCA regimen for simulation consisted of $15 \mu \mathrm{g} / \mathrm{ml}$ fentanyl that was administered according to the standard clinical practice guidelines at the author's institution, i.e., IV bolus loading of $2 \mu \mathrm{g} / \mathrm{kg}$ followed by demand boluses of $15 \mu \mathrm{g}$ with $15 \mu \mathrm{g} / \mathrm{h}$ background infusion. The lockout interval was 15 minutes. In this simulation, a loading dose of IV fentanyl was administered 1 hour before the end of surgery and IV PCA was started from the end of surgery. With this regimen of fentanyl, MEAC was reached 5 hours after the end of surgery. The $90 \%$ steady-state concentration was achieved

\section{B}

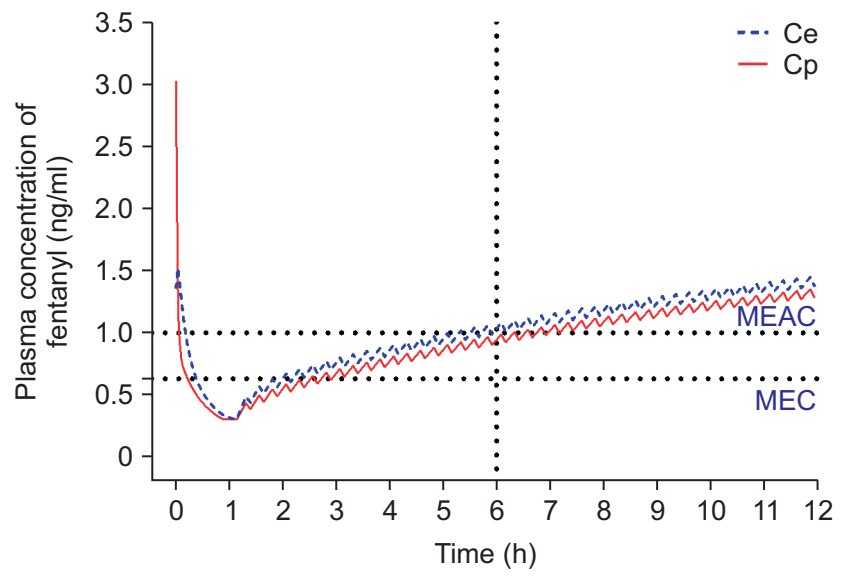

Fig. 4. Predicted concentration of fentanyl in the plasma over time after administration of an IV bolus of $2 \mu \mathrm{g} / \mathrm{kg}$ followed by demand boluses of $15 \mu \mathrm{g}$ every 15 minutes and background infusion of $15 \mu \mathrm{g} / \mathrm{h}$. (A) The entire time-concentration curve. (B) Time-concentration curve of time to reach MEAC. (C) Time-concentration curve of time to reach $90 \%$ steadystate concentration of fentanyl. MEAC: minimum effective analgesic concentration, MEC: minimum effective concentration. Demand bolus, background infusion rate, and lock-out time of postoperative IV patientcontrolled analgesia (IV PCA) were set at $1 \mathrm{ml}, 1 \mathrm{ml} / \mathrm{h}$, and 15 minutes, respectively. The concentration of fentanyl in IV PCA was $15 \mu \mathrm{g} / \mathrm{ml}$. The pharmacokinetic model of Scott et al. was applied to this simulation [44]. Vertical dotted lines indicated time to reach MEAC ( 6 hours) and $90 \%$ steady-state concentration (18.5 hours). Time 0 indicates 1 hour before the end of surgery. 
17.5 hours after the end of surgery, and steady-state concentration $(1.8 \mathrm{ng} / \mathrm{ml})$ was double the MEAC $(1 \mathrm{ng} / \mathrm{ml})$ of fentanyl (Fig. 4). MEAC and 90\% steady-state concentration were reached more quickly with IV PCA with oxycodone compared to fentanyl.

\section{Summary}

Since the approval of IV oxycodone as a patient-controlled analgesic, the use of IV patient-controlled analgesia with oxycodone is increasing gradually in Korea. Although the approved dosage regimen for postoperative pain relief with IV oxycodone involves IV bolus loading of $2 \mathrm{mg}$ followed by patient-controlled analgesia with demand bolus of $1 \mathrm{mg}$ and no background infusion, the MEAC of oxycodone was reached most quickly with a higher loading dose $(0.1 \mathrm{mg} / \mathrm{kg})$ and IV PCA with background infusion. When a potency ratio of morphine to fentanyl of $100: 1$ was applied, oxycodone showed similar, and sometimes better, effects on postoperative analgesia compared with fentanyl. Oxycodone is a good alternative to fentanyl in postoperative pain management. However, it is necessary to reduce the analgesic dose of oxycodone in elderly patients because metabolic clearance decreases with age.

\section{References}

1. Kalso E. Oxycodone. J Pain Symptom Manage 2005; 29(5 Suppl): S47-56.

2. Sjövall S, Kokki M, Kokki H. Laparoscopic surgery: a narrative review of pharmacotherapy in pain management. Drugs 2015; 75: 1867-89.

3. Koch S, Ahlburg P, Spangsberg N, Brock B, Tønnesen E, Nikolajsen L. Oxycodone vs. fentanyl in the treatment of early post-operative pain after laparoscopic cholecystectomy: a randomised double-blind study. Acta Anaesthesiol Scand 2008; 52: 845-50.

4. Lenz H, Sandvik L, Qvigstad E, Bjerkelund CE, Raeder J. A comparison of intravenous oxycodone and intravenous morphine in patientcontrolled postoperative analgesia after laparoscopic hysterectomy. Anesth Analg 2009; 109: 1279-83.

5. Ross FB, Smith MT. The intrinsic antinociceptive effects of oxycodone appear to be kappa-opioid receptor mediated. Pain 1997; 73: 151-7.

6. Smith MT. Differences between and combinations of opioids re-visited. Curr Opin Anaesthesiol 2008; 21: 596-601.

7. Nozaki C, Saitoh A, Kamei J. Characterization of the antinociceptive effects of oxycodone in diabetic mice. Eur J Pharmacol 2006; 535: 145-51.

8. Nozaki C, Kamei J. Involvement of mu1-opioid receptor on oxycodone-induced antinociception in diabetic mice. Eur J Pharmacol 2007; 560: $160-2$.

9. Silvasti M, Rosenberg P, Seppälä T, Svartling N, Pitkänen M. Comparison of analgesic efficacy of oxycodone and morphine in postoperative intravenous patient-controlled analgesia. Acta Anaesthesiol Scand 1998; 42: 576-80.

10. Brittain GJ. Dihydrohydroxycodeinone pectinate. Lancet 1959; 2: 544-6.

11. Park JH, Lee C, Shin Y, An JH, Ban JS, Lee JH. Comparison of oxycodone and fentanyl for postoperative patient-controlled analgesia after laparoscopic gynecological surgery. Korean J Anesthesiol 2015; 68: 153-8.

12. Kokki M, Broms S, Eskelinen M, Rasanen I, Ojanperä I, Kokki H. Analgesic concentrations of oxycodone--a prospective clinical PK/PD study in patients with laparoscopic cholecystectomy. Basic Clin Pharmacol Toxicol 2012; 110: 469-75.

13. Pesonen A, Suojaranta-Ylinen R, Hammarén E, Tarkkila P, Seppälä T, Rosenberg PH. Comparison of effects and plasma concentrations of opioids between elderly and middle-aged patients after cardiac surgery. Acta Anaesthesiol Scand 2009; 53: 101-8.

14. Camu F, Vanlersberghe C. Pharmacology of systemic analgesics. Best Pract Res Clin Anaesthesiol 2002; 16: 475-88.

15. Gourlay GK, Kowalski SR, Plummer JL, Cousins MJ, Armstrong PJ. Fentanyl blood concentration-analgesic response relationship in the treatment of postoperative pain. Anesth Analg 1988; 67: 329-37.

16. Grönlund J, Saari TI, Hagelberg NM, Neuvonen PJ, Laine K, Olkkola KT. Effect of inhibition of cytochrome P450 enzymes 2D6 and 3A4 on the pharmacokinetics of intravenous oxycodone: a randomized, three-phase, crossover, placebo-controlled study. Clin Drug Investig 2011; 31: 143-53.

17. Korjamo T, Tolonen A, Ranta VP, Turpeinen M, Kokki H. Metabolism of oxycodone in human hepatocytes from different age groups and prediction of hepatic plasma clearance. Front Pharmacol 2012; 2: 87.

18. Söderberg Löfdal KC, Andersson ML, Gustafsson LL. Cytochrome P450-mediated changes in oxycodone pharmacokinetics/ pharmacodynamics and their clinical implications. Drugs 2013; 73: 533-43.

19. Lalovic B, Kharasch E, Hoffer C, Risler L, Liu-Chen LY, Shen DD. Pharmacokinetics and pharmacodynamics of oral oxycodone in healthy human subjects: role of circulating active metabolites. Clin Pharmacol Ther 2006; 79: 461-79.

20. Kalso E. How different is oxycodone from morphine? Pain 2007; 132: 227-8.

21. Nieminen TH, Hagelberg NM, Saari TI, Pertovaara A, Neuvonen M, Laine K, et al. Rifampin greatly reduces the plasma concentrations of intravenous and oral oxycodone. Anesthesiology 2009; 110: 1371-8.

22. Saari TI, Grönlund J, Hagelberg NM, Neuvonen M, Laine K, Neuvonen PJ, et al. Effects of itraconazole on the pharmacokinetics and pharmacodynamics of intravenously and orally administered oxycodone. Eur J Clin Pharmacol 2010; 66: 387-97.

23. Zwisler ST, Enggaard TP, Mikkelsen S, Brosen K, Sindrup SH. Impact of the CYP2D6 genotype on post-operative intravenous oxycodone 
analgesia. Acta Anaesthesiol Scand 2010; 54: 232-40.

24. Stamer UM, Zhang L, Book M, Lehmann LE, Stuber F, Musshoff F. CYP2D6 genotype dependent oxycodone metabolism in postoperative patients. PLoS One 2013; 8: e60239.

25. Droll K, Bruce-Mensah K, Otton SV, Gaedigk A, Sellers EM, Tyndale RF. Comparison of three CYP2D6 probe substrates and genotype in Ghanaians, Chinese and Caucasians. Pharmacogenetics 1998; 8: 325-33.

26. Xie HG, Kim RB, Wood AJ, Stein CM. Molecular basis of ethnic differences in drug disposition and response. Annu Rev Pharmacol Toxicol 2001; 41: 815-50.

27. Heim MH, Meyer UA. Evolution of a highly polymorphic human cytochrome P450 gene cluster: CYP2D6. Genomics 1992; 14: 49-58.

28. Garcia-Barceló M, Chow LY, Lam KL, Chiu HF, Wing YK, Waye MM. Occurrence of CYP2D6 gene duplication in Hong Kong Chinese. Clin Chem 2000; 46: 1411-3.

29. Kubota T, Yamaura Y, Ohkawa N, Hara H, Chiba K. Frequencies of CYP2D6 mutant alleles in a normal Japanese population and metabolic activity of dextromethorphan O-demethylation in different CYP2D6 genotypes. Br J Clin Pharmacol 2000; 50: 31-4.

30. Lee SJ, Lee SS, Jung HJ, Kim HS, Park SJ, Yeo CW, et al. Discovery of novel functional variants and extensive evaluation of CYP2D6 genetic polymorphisms in Koreans. Drug Metab Dispos 2009; 37: 1464-70.

31. Bertilsson L, Dahl ML, Dalén P, Al-Shurbaji A. Molecular genetics of CYP2D6: clinical relevance with focus on psychotropic drugs. Br J Clin Pharmacol 2002; 53: 111-22.

32. Marez D, Legrand M, Sabbagh N, Lo Guidice JM, Spire C, Lafitte JJ, et al. Polymorphism of the cytochrome P450 CYP2D6 gene in a European population: characterization of 48 mutations and 53 alleles, their frequencies and evolution. Pharmacogenetics 1997; 7: $193-202$.

33. Gaedigk A, Gotschall RR, Forbes NS, Simon SD, Kearns GL, Leeder JS. Optimization of cytochrome P4502D6 (CYP2D6) phenotype assignment using a genotyping algorithm based on allele frequency data. Pharmacogenetics 1999; 9: 669-82.

34. Bradford LD. CYP2D6 allele frequency in European Caucasians, Asians, Africans and their descendants. Pharmacogenomics 2002; 3: 229-43.

35. Lennard MS, Iyun AO, Jackson PR, Tucker GT, Woods HF. Evidence for a dissociation in the control of sparteine, debrisoquine and metoprolol metabolism in Nigerians. Pharmacogenetics 1992; 2: 89-92.

36. Liukas A, Kuusniemi K, Aantaa R, Virolainen P, Neuvonen M, Neuvonen PJ, et al. Elimination of intravenous oxycodone in the elderly: a pharmacokinetic study in postoperative orthopaedic patients of different age groups. Drugs Aging 2011; 28: 41-50.

37. Saari TI, Ihmsen H, Neuvonen PJ, Olkkola KT, Schwilden H. Oxycodone clearance is markedly reduced with advancing age: a population pharmacokinetic study. Br J Anaesth 2012; 108: 491-8.

38. Ordóñez Gallego A, González Barón M, Espinosa Arranz E. Oxycodone: a pharmacological and clinical review. Clin Transl Oncol 2007; 9: 298-307.

39. Kokki M, Broms S, Eskelinen M, Neuvonen PJ, Halonen T, Kokki H. The analgesic concentration of oxycodone with co-administration of paracetamol -- a dose-finding study in adult patients undergoing laparoscopic cholecystectomy. Basic Clin Pharmacol Toxicol 2012; 111: 391-5.

40. Tanskanen P, Kyttä J, Randell T. Patient-controlled analgesia with oxycodone in the treatment of postcraniotomy pain. Acta Anaesthesiol Scand 1999; 43: 42-5.

41. Pereira J, Lawlor P, Vigano A, Dorgan M, Bruera E. Equianalgesic dose ratios for opioids. a critical review and proposals for long-term dosing. J Pain Symptom Manage 2001; 22: 672-87.

42. Hwang BY, Kwon JY, Kim E, Lee DW, Kim TK, Kim HK. Oxycodone vs. fentanyl patient-controlled analgesia after laparoscopic cholecystectomy. Int J Med Sci 2014; 11: 658-62.

43. Kim NS, Kang KS, Yoo SH, Chung JH, Chung JW, Seo Y, et al. A comparison of oxycodone and fentanyl in intravenous patient-controlled analgesia after laparoscopic hysterectomy. Korean J Anesthesiol 2015; 68: 261-6.

44. Scott JC, Stanski DR. Decreased fentanyl and alfentanil dose requirements with age. A simultaneous pharmacokinetic and pharmacodynamic evaluation. J Pharmacol Exp Ther 1987; 240: 159-66. 